\title{
Design of Bio Digester for CMR Technical Campus Hostel Using Kitchen Waste
}

\author{
M. Ahmed Ali Baig ${ }^{1}$, Khasim Sharif Sk $^{2}$, G.S.N.Murthy ${ }^{3}$, K. Ramu ${ }^{4}$ \\ ${ }^{1}$ Professor, Mechanical Engineering Department, CMR Technical Campus, Hyderabad, JNTUH, India \\ ${ }^{2}$ Assistant professor Mechanical Engineering Department, CMR Technical Campus, Hyderabad, JNTUH, India \\ ${ }^{3}$ Professor, H\&S Department, CMR Technical Campus, Hyderabad, JNTUH, India CMRTC/JNTUH, India \\ ${ }^{4}$ Student, Mechanical Engineering Department, CMR Technical Campus, Hyderabad, JNTUH, India
}

\begin{abstract}
Biomass is a versatile energy source that can be used for production of heat, power, transport fuels and biomaterials, apart from making a significant contribution to climate change mitigation. The terms biomass energy, bioenergy and biofuels cover any energy products derived from plant or animal or organic material. The work presented in this paper is an attempt towards utilization of abundantly available biomass in different forms around us. The source of biomass considered for this study is the kitchen waste available from CMR Technical Campus hostel, Hyderabad. The paper presents the volume of biomass available at the said location and the effective ways of utilizing it. The most reliable source of biomass conversion, i.e. Bio digester is chosen as an energy convertor. After conducting a survey about the type and quantity of the waste, an attempt is made to design a biogas digester which suits to nature and quantity of waste. Thus it is planned to produce biogas from the bio digester and the same be used for cooking purpose in hostel, in effect contributing to saving of energy.
\end{abstract}

Keywords: Anaerobic digestion, Biogas, Kitchen waste, Bio Digester

\section{Introduction}

Biomass energy systems have the potential to address many environmental issues, especially global warming and greenhouse gases emissions, and foster sustainable development among poor communities. Biomass fuel sources are readily available in rural and urban areas of all countries. Biomass-based industries can provide appreciable employment opportunities and promote biomass re-growth through sustainable land management practices. The increasing interest in biomass energy and biofuels has been the result of the associated benefits like Potential to reduce GHG emissions, Energy security benefits, Substitution for diminishing global oil supplies, Potential impacts on waste management strategy, Capacity to convert a wide variety of wastes into clean energy, Technological advancement in thermal and biochemical processes for waste-to-energy transformation. Biochemical processes, like anaerobic digestion and sanitary landfills, can also produce clean energy in the form of biogas and producer gas which can be converted to power and heat using a gas engine.

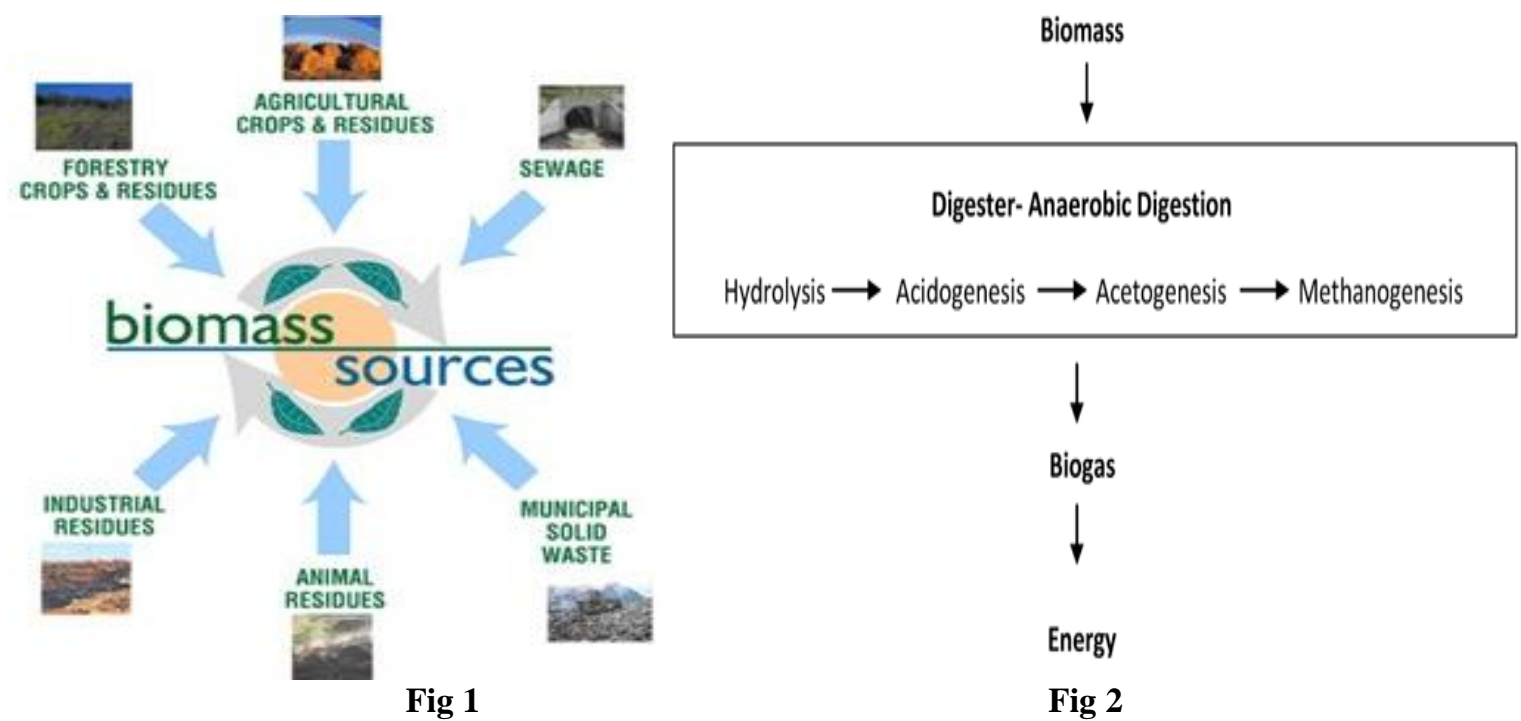

International Conference on Recent Innovations in Civil \& Mechanical Engineering

[i-CAM2K16] DOI: 10.9790/1684-160530498103 
Biogas is produced through the breakdown of organic matter in the absence of oxygen, which is referred to as anaerobic digestion. The whole process works like a big concrete stomach would: Organic materials like manure, food scraps, crop residue, or wastewater sludge (known as feedstock) are fed into the digester, where it's heated to 38-40 degrees Celsius (temperature of a cow's stomach) and stirred for 30-60 days, slowly producing a combination of methane, carbon dioxide and other gases (known as biogas). The biogas can then be used for power generation, heating and cooling needs or piped into the natural gas grid. Anaerobic digestion is a multistep biological and chemical process that is beneficial in not only waste management but also energy creation. There are four fundamental steps of anaerobic digestion that include hydrolysis, acidogenesis, acetogenesis, and methanogenesis. Throughout this entire process, large organic polymers that make up Biomass are broken down into smaller molecules by chemicals and microorganisms. Upon completion of the anaerobic digestion process, the Biomass is converted into Biogas, namely carbon dioxide and methane, as well as digestate and wastewater.

\section{Literature Survey}

Callaghan et al (2002)[1] conducted studies on continuous codigestion of cattle slurry (CS) with fruit and vegetable wastes (FVW) and chicken manure (CM) and reported that, $\mathrm{CM}$ is not suitable as co-substrate. As the amount of CM in the feed and the organic loading was increased, the 37 VS reduction deteriorated and the methane yield decreased due to the presence of free ammonia in the liquor. Two-phase anaerobic digestion of a mixture of fruit and vegetable wastes was studied using anaerobic sequencing batch reactors operated at mesophilic temperature by Bouallagui et al (2004)[2]. It was reported that $81 \%$ of hydrolysis yield was achieved at an OLR of $7.5 \mathrm{~g}$ COD/L.d. Volatile fatty acids concentration reached a maximum value of $13.3 \mathrm{~g} / \mathrm{L}$ at a loading rate of $10.1 \mathrm{~g}$ COD/L.d. Kaparaju and Rintala (2005)[3] have carried out co-digestion studies using organic residues from potato tuber with pig manure at a loading rate of $2 \mathrm{~kg} \mathrm{VS} / \mathrm{m} 3$ / day in CSTR at 350C and they observed that, the methane yield and process performance for potato tuber is similar to that of its industrial residues. Dearman and Bentham (2007)[4] carried out studies on anaerobic digestion of food waste and the comparing leachate exchange rates in sequential batch systems for digestion of food waste and bio-solids. The studies revealed that, by increasing the leachate volume between mature and start-up reactors, the time to degrade feedstock decreased, but total methane generation yield did not markedly differ, being $229 \mathrm{~L} \mathrm{CH} 4 / \mathrm{kg} \mathrm{V}$ Sadded and $214 \mathrm{~L} \mathrm{CH} 4 / \mathrm{kg}$ V Sadded. From the analysis of biogas composition, the changes in carbon-di-oxide and methane content in mature reactors were observed due to stress caused by the addition of leachate with high VFA concentrations from the start-up reactors.

Tembhurkar and Mhaisalkar (2007)[5] carried out studies on hydrolysis and acidogenesis of kitchen wastes in two phase anaerobic digester and the specific rate constant $(\mathrm{k})$ during hydrolysis and acidification of kitchen waste was $0.155 \mathrm{~d}-1$. Anaerobic co-digestion of vegetable market waste and sewage sludge seems to be an attractive method for waste 38 management, environmental protection, and energy savings (Anhuradha et al 2007)[6]. Anaerobic co-digestion of kitchen waste (KW) with cattle manure (CM) for biogas production was investigated by $\mathrm{Li}$ et al (2009). The codigestion of KW with $\mathrm{CM}$ increased the methane yield by $44 \%$ as compared to the single digestion of KW alone. The reason for enhanced methane generation was the synergistic effect in the co-digestion process. The effect of abattoir wastewater (AW), fish waste, waste activated sludge (WAS) addition as co-substrates for the fruit and vegetable waste on anaerobic digestion performance was investigated in mesophilic condition using anaerobic sequential batch reactors by Bouallagui et al (2009)[2] at an organic loading rate of 2.46-2.51 g volatile solids (VS)/L/day. It was observed from the studies that, the AW and WAS addition at a ratio of $10 \%$ VS, enhanced the biogas yield by $51.5 \%$ and $43.8 \%$ and total volatile solids removal by $10 \%$ and $11.7 \%$ respectively. However FW addition led to improvement of the process stability, as indicated by the low VFAs/Alkalinity ratio of 0.28 . The behavior of co-digestion of cow manure with food waste by applying increasing concentrations of intermittent pulses of residual-oil generated from a canned fish processing industry was investigated by Neves et al (2009b). Considering the mixture of lipids present in the oily waste, addition of oily waste at $12 \mathrm{~g}$ COD oil /Lreactor enhanced the methane production in the codigestion of cow manure and food waste. But further addition of oily waste to $18 \mathrm{~g}$ COD oil /L reactor induced a persistent inhibition of the process, detected by the decrease in $\mathrm{pH}$ to a minimum of 6.5 and an increase in effluent soluble COD and VFA. 39 Co-digestion of different biodegradable waste streams from the food and agriculture industry sectors in Cyprus was investigated by Monou et al (2009) and a rapid screening procedure to optimize the co-digestion process was established. The role of trace elements in anaerobic co-digestion was investigated by Zhang et al (2011). The co-digestion of the food waste with the piggery wastewater showed a high methane production rate without VFA accumulation. The reason for enhancement of methane production was due to trace elements supplemented from piggery wastewater during co-digestion with food waste. 


\section{Fixed-dome Plants}

\section{Types Of Bio Gas Digester}

A fixed-dome plant consists of a digester with a fixed, non-movable gas holder, which sits on top of the digester. When gas production starts, the slurry is displaced into the compensation tank. Gas pressure increases with the volume of gas stored and the height difference between the slurry level in the digester and the slurry level in the compensation tank.

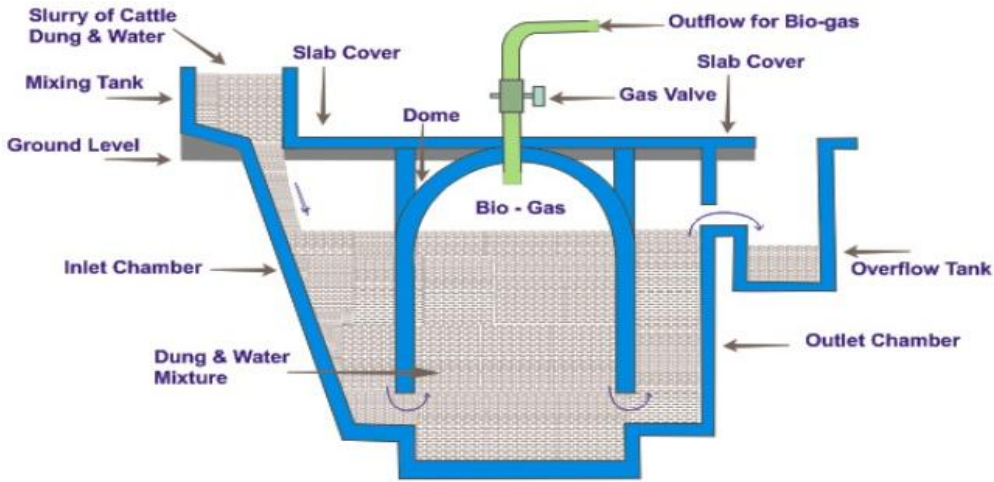

Fig 3. Fixed-dome type Bio-gas Plant

The costs of a fixed-dome biogas plant are relatively low. It is simple as no moving parts exist. There are also no rusting steel parts and hence a long life of the plant (20 years or more) can be expected. The plant is constructed underground, protecting it from physical damage and saving space. While the underground digester is protected from low temperatures at night and during cold seasons, sunshine and warm seasons take longer to heat up the digester. No day/night fluctuations of temperature in the digester positively influence the bacteriological processes. The construction of fixed dome plants is labor-intensive, thus creating local employment. Fixed-dome plants are not easy to build. They should only be built where construction can be supervised by experienced biogas technicians. Otherwise plants may not be gas-tight (porosity and cracks).

\section{Janata model:}

Janata model was the first fixed-dome design in India, as a response to the Chinese fixed dome plant. It is not constructed anymore. The mode of construction leads to cracks in the gasholder - very few of this plant had been gas-tight [7].

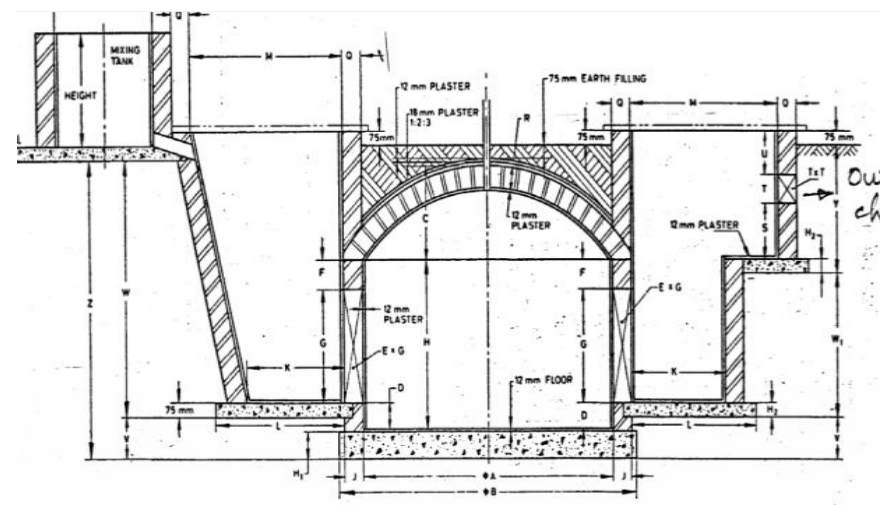

Fig: 4. Janata model Construction of digester

Successful construction of the biogas plant requires a proper design and adherence to follow correct construction methods. The success or failure of any biogas plant primarily depends upon the quality of construction work. The following instructions are based on the step-by-step instructions from the Government of Nepal Biogas Support Program Gobar Gas and Agricultural Equipment Development Company of Nepal has developed the design for model 2047 biogas plant. This biogas plant model has become prolific across Asia and is known as a fixed-dome plant. The advantages of the fixed dome plant include the simplicity of design, few moving parts, low cost to construct and low maintenance. The disadvantages when compared to a floating-dome digester are primarily the inability to store gas for use on demand; gas from the fixed dome digester must be used as generated or expelled to avoid damaging the digester. 


\section{Floating type model digester}

In the past, floating-drum plants were mainly built in India and are therefore referred to as Indian drum biogas digesters or Indian floating cover biogas digesters. Floating-drum plants are used chiefly for digesting animal and human faces on a continuous-feed mode of operation, i.e. with daily input. They are used most frequently by small- to middle-sized farms (digester size: $5-15 \mathrm{~m}^{3}$ ) or in institutions and larger agro-industrial estates (digester size: $20-100 \mathrm{~m}^{3}$ ). A floating-drum plant consists of a cylindrical or dome-shaped digester and a moving, floating gas-holder, or drum. The gas-holder floats either directly in the fermenting slurry or in a separate water jacket. The drum in which the biogas collects has an internal and/or external guide frame that provides stability and keeps the drum upright. If biogas is produced, the drum moves up, if gas is consumed, the gas-holder sinks back. Floating-drum plants are easy to understand and operate. They provide gas at a constant pressure, and the stored gas-volume is immediately recognizable by the position of the drum. Gas-tightness is no problem, provided the gasholder is de-rusted and painted regularly.

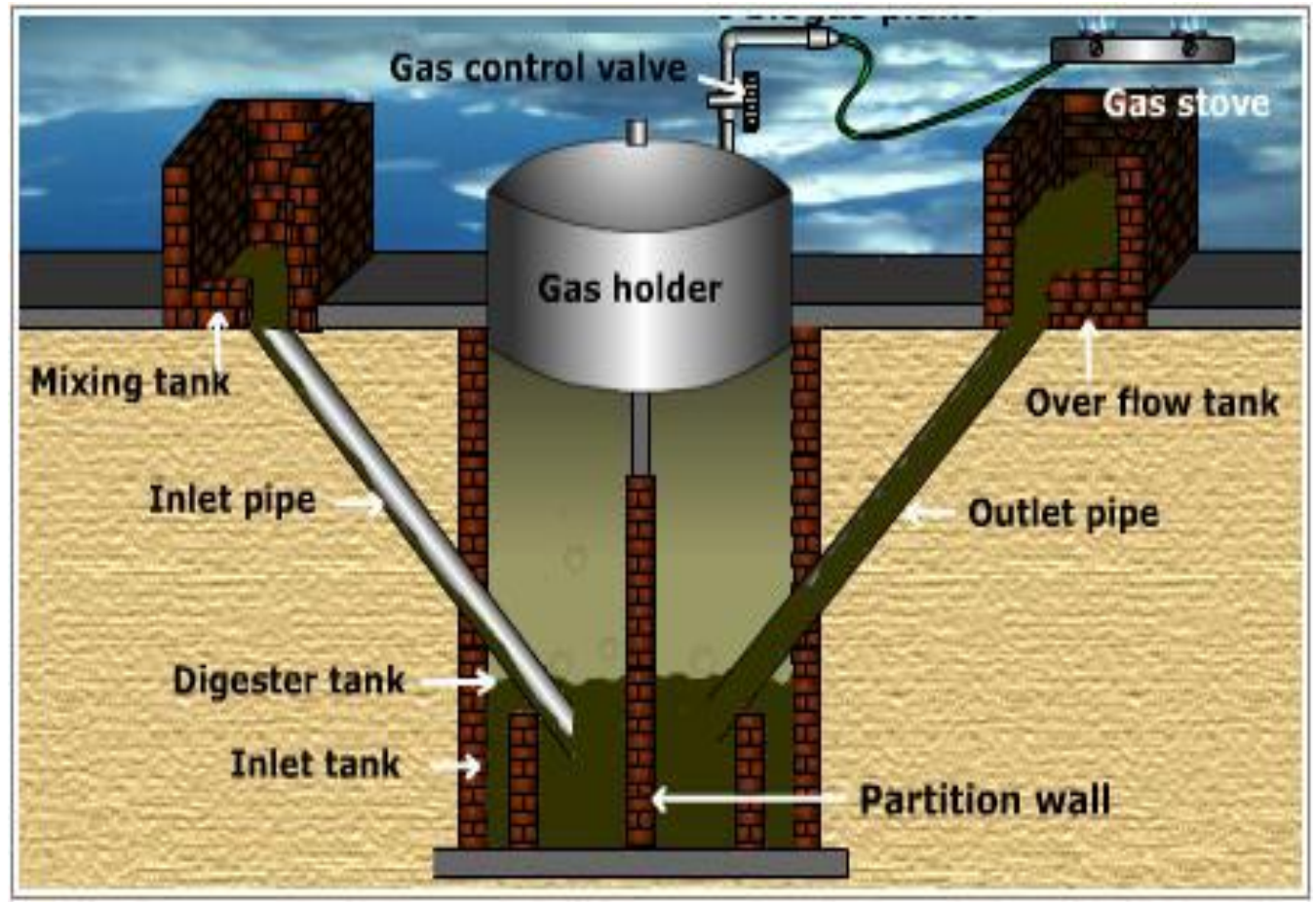

Fig 5 Floating type model Construction of digester

\section{Survey Of Kitchen Waste}

I. Number of occupants in the hostel -550

II. Vegetables waste- $10 \mathrm{Kg}$

III. Food waste- $35 \mathrm{Kg}$

IV. Total vegetables and food waste $-45 \mathrm{Kg}$

V. Occupancy period 321 days

VI. Number of cycles of waste availability- 3

The food waste contains of the left food by the students which varies between $40 \mathrm{Kg}$ to $45 \mathrm{Kg}$. For particular study an average of $45 \mathrm{Kg}$ is considered. The Vegetables waste varies with menu. The vegetables waste varies from $8 \mathrm{kgs}$ to $11 \mathrm{Kg}$.For particular study on an average $10 \mathrm{Kg}$ is considered. The data presented above is monthly average waste generated; otherwise the waste peaks during any event of the hostel/college.

\section{Design Of Bio Gas Digester}

In accordance with the results of the survey, the design of the digester is prepared. The fixed dome type bio digester is selected for meeting the purpose. Fixed dome type bio digester has advantages like low construction cost, no moving parts, no rusting steel parts, hence long life (20 years or more), underground construction, affording protection from winter cold and saving space, creates employment locally. Sturdy and possible to build from cheap, inexpensive materials. Unobtrusive- typically buried. Well insulated. The underground design combined with typically porous building materials allows the bio digester to remain at a productive temperature for longer. 


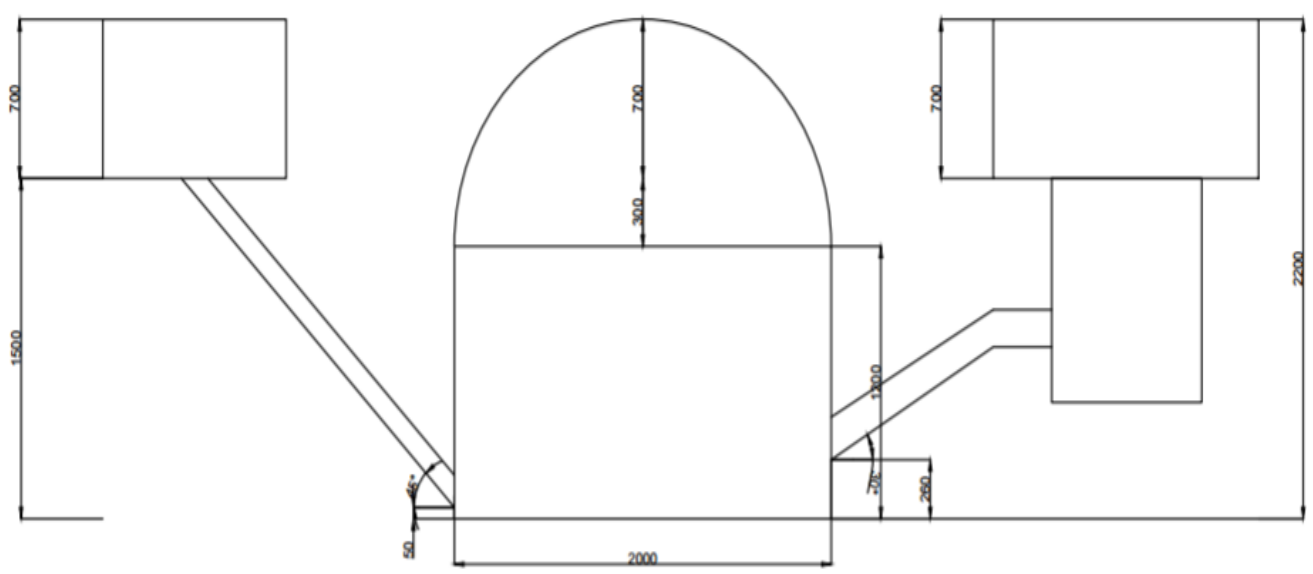

Fig 6 Construction model of proposed Biogas Plant

The calculations for design the bio digester are follows.

\section{Cylinder}

$\mathrm{V}=\pi / \mathrm{r}^{2}$

Height $(\mathrm{h})=150 \mathrm{~cm}(1.5 \mathrm{~m})$

Diameter $=200 \mathrm{~cm}(2 \mathrm{~m})$

$\mathrm{V}=(3.14) * 1^{2} *(1.5)$

$\mathrm{V}=4.71 \mathrm{~m}^{3}$

$\mathrm{V}=4710$ liters

\section{Semi sphere}

$\mathrm{V}=2 / 3 \sqsubset \mathrm{r}^{3}$

Height $=100 \mathrm{~cm}(1 \mathrm{~m})$

Diameter $=200 \mathrm{~cm}(2 \mathrm{~m})$

$\mathrm{V}=(2 / 3) *(3.14) * 13$

$\mathrm{V}=2.093 \mathrm{~m}^{3}$

$\mathrm{V}=2093$ liters

Total volume $=$ cylinder volume + semi sphere

$$
\begin{aligned}
& =4710 \text { liters }+2093 \text { liters } \\
& =6803 \text { liters } \\
& =6.803 \mathrm{~m}^{3}
\end{aligned}
$$

Specification calculations:

For one day,

For 30 days $(40 \mathrm{Kg}$ slurry $)+(80 \mathrm{Kg}$ of water $)$ i.e. $(1: 2)=120 \mathrm{Kg}$ $\longrightarrow 3600 \mathrm{Kg}$ or $3.6 \mathrm{~m}^{3}$

\section{Slurry occupancy}

$1 \mathrm{~cm}-31.4$ liters

$5 \mathrm{~cm}-157$ liters

$15 \mathrm{~cm}-471$ liters

$36 \mathrm{~cm}-1130$ liters

$143 \mathrm{~cm}-4490$ liters.

Time taken to fill the digester (cylinder):

\begin{tabular}{|l|l|l|}
\hline Time & Slurry Weight & Slurry Occupancy \\
\hline 1 day & $120 \mathrm{Kg}$ & $3.82 \mathrm{~cm}$ \\
\hline 5 days & $600 \mathrm{Kg}$ & $19.10 \mathrm{~cm}$ \\
\hline 10 days & $120 \mathrm{Kg}$ & $38.20 \mathrm{~cm}$ \\
\hline 30 days & $3600 \mathrm{Kg}$ & $115 \mathrm{~cm}$ \\
\hline
\end{tabular}




\section{Conclusion}

From the results presented in the above section, it is evident that for a kitchen waste of $45 \mathrm{Kg}$, the volume of digester required is $6.803 \mathrm{~m}^{3}$, considering fixed dome type model. And a digester of $6.803 \mathrm{~m}^{3}$ working with kitchen waste as feed is estimated to generate $3.6 \mathrm{~m}^{3}$ volume of biogas. The present work is limited till the design of the digester, further the methods to increase the gas productions rate with different admixtures will be studied. The economic calculations presenting the savings in terms of Conventional LPG gas used are to be worked and presented in continuation of this work.

\section{References}

[1]. FJ Callaghan, DAJ Wase, K Thayanithy Continuous co-digestion of cattle slurry with fruit and vegetable wastes and chicken manure, Biomass and bioenergy, 2002 - Elsevier

[2]. Bouallagui, H., Y. Touhami, R. Ben Cheikh, and M. Hamdi. 2005. Bioreactor Performance in Anaerobic Digestion of Fruit and Vegetable Wastes. Process Biochemistry 40(3-4): 989-995.

[3]. Bioethanol, biohydrogen and biogas production from wheat straw in a biorefinery concept P Kaparaju, M Serrano, AB Thomsen, P Kongjan, I Angelidaki,Bioresource Technology 100 (9), 2562-2568

[4]. Anaerobic digestion of food waste: comparing leachate exchange rates in sequential batch systems digesting food waste and biosolids. Dearman B ${ }^{1}$, Bentham RH. Waste Manag. 2007;27(12):1792-9. Epub 2006 Oct 19.

[5]. Hydrolysis and Acidogenesis of Kitchen Waste in 2 Phase A. R. Tembhurkar and V. A. Mhaisalkar Journal of the IPHE, India, Vol. 2007-08 No. 2. Page 2.

[6]. Anhuradha, S; Vijayagopal, V; Radha, P; Ramanujam, R (2007).Kinetic Studies and Anaerobic Co-digestion of Vegetation Market and Sewage Slugde, CLEAN-Soil, Air, Water Vol. 35 pp 197-199.

[7]. Singh, Jasvinder, and Sai Gu. "Biomass conversion to energy in India - a critique." Renewable and Sustainable Energy Reviews 14.5 (2010): 1367-1378. 